\title{
EN TORNO A SANTA TERESA Y SU PROYECCIÓN. HISTORIA Y MEMORIA EN 2015
}

\author{
ABOUT ST. TERESA OF AVILA AND HER PROJECTION. \\ HISTORY AND MEMORY IN 2015
}

POR

\section{ÁNGELA ATIENZA LÓPEZ*}

Universidad de La Rioja

Sobre santa Teresa y sobre su vida, su huella y su legado, se han escrito miles y miles de páginas. Impresiona la recopilación de referencias que Manuel Diego Sánchez publicó en 2008 bajo el título de «Bibliografía sistemática de Santa Teresa de Jesús»: ${ }^{1}$ algo más de 12.500 títulos. Naturalmente, todo tipo de plumas, todo tipo de planteamientos y todo tipo de intenciones palpitan detrás de todo este inmenso caudal bibliográfico, que incorpora también el registro de las ediciones de las obras de Teresa, las críticas y las demás, las de cada uno de sus textos y las de sus obras completas, incluyendo el epistolario.

Una buena parte de esta producción inmensa se fecha con anterioridad a 1982, el año en el que se conmemoraba el IV centenario de la muerte de la madre Teresa. Con ocasión de esta efemérides, uno de los mejores historiadores y más reconocido estudioso de santa Teresa, excelente conocedor de la producción historiográfica desplegada sobre ella, el profesor Teófanes Egido, presentaba un balance historiográfico de lo publicado hasta el momento.

Los miles de referencias acumuladas hasta aquel 1982 y el aluvión de páginas reunidas permitirían pensar a cualquier persona que Santa Teresa era una verdadera privilegiada por la atención y el interés que había concitado y aún

* La coordinación de este dossier monográfico y su presentación ha sido realizado en el marco del Proyecto de Investigación de referencia HAR2011-28732-C03-02, financiado por el Ministerio de Economía y Competitividad.

${ }^{1}$ Diego Sánchez, M. 2008. Bibliografía sistemática de Santa Teresa de Jesús. Madrid: Editorial de Espiritualidad. 
sería posible concluir que sobre su figura, su trayectoria, su impacto... posiblemente no quedara mucho que aportar. Bien, pues frente a esta conjetura radiante y feliz, el profesor Egido, comenzaba su contribución con un juicio contundente:

«Definitivamente, Santa Teresa ha tenido mala suerte desde la perspectiva histórica». ${ }^{2}$

Su explicación era la siguiente: «... al igual que sucediera con el espoleo que supuso su declaración como doctora de la Iglesia, y aunque sea pronto para establecer conclusiones, las primicias del cuarto centenario de su muerte confirman la realidad del rapto teresiano por espiritualistas y doctrinarios».

Una santa Teresa raptada por espiritualistas y doctrinarios... Creo que hay en este retrato que presenta el profesor Egido un inteligente juego retórico, muy certero: esa Teresa raptada remite a la realidad de una santa Teresa absorta en sus raptos y arrobos, efectivamente la imagen en la que se ha insistido y con la que se ha trabajado, la de una Teresa ausente, fuera del mundo y del siglo, congelada y atemporal. Esta es básicamente la imagen que ha estado dominando durante tanto tiempo las aproximaciones biográficas a su figura y la que se corresponde también con la iconografía más reproducida.

Lo que estaba detrás de todo este torrente bibliográfico en buena medida eran productos literarios que escapaban del quehacer histórico riguroso y de sus requerimientos, configurando una historiografía biográfica teresiana que discurría por los cauces de la hagiografía y que ofrecía semblanzas biográficas construidas más con ojos y lentes de religión y de doctrina que de historia y de ciencia histórica.

Hoy han transcurrido ya algo más de treinta años de aquel balance. ¿Qué ha cambiado?.

Ciertamente, subsisten las aportaciones que nos siguen devolviendo la figura mística, la universal y ejemplar, que continúan insistiendo en el semblante atemporal de santa Teresa. Pero también es bien visible que aquella llamada de atención del profesor Egido ${ }^{3}$-que ya apuntaba también los «temas nuevos y últimos logros» que se iban abriendo paso- y las perspectivas de investigación que se han ido desarrollando han cambiado el panorama historiográfico y están permitiendo rescatar a santa Teresa del secuestro -por mantener el mismo símil- en el que se hallaba confinada. En 1997 se podía perfilar ya un paisaje diferente y un horizonte de recuperación. ${ }^{4}$

\footnotetext{
${ }^{2}$ Egido, T. 1982. «Santa Teresa y las tendencias de la historiografía actual». Teresianum, 33 : 159-180.

${ }^{3}$ «... ya es hora de que se vayan aquilatando su mito de universalismo y ejemplaridad omnivalente con el contraste de las condiciones objetivas en que se desarrolló su existencia, se realizó su reforma y escribió su mensaje». Ibid: 159.

${ }^{4}$ El mismo T. Egido reconocía que «han llegado las innovaciones». Egido, T. 1997. «La biografía teresiana y nuevas claves de comprensión histórica», en S. Ros García (coord.); La recepción de los
} 
Y es posible entonces afirmar que hoy sí hemos avanzado en una historia de la Teresa histórica, la que nos ofrece una imagen de ella viva, más viva que la Teresa «arrobada», «extática», que esa Teresa efectivamente raptada, perdida en sus raptos, la Teresa fuera del mundo, de su mundo y de su tiempo.

Pero también cabe preguntarse hasta dónde ha llegado esta nueva composición elaborada con los criterios de rigor histórico que se exigen, cuál es la percepción de santa Teresa que se mantiene en los medios sociales, fuera del ámbito especializado y académico, la imagen que se difunde y que sigue predominando en el imaginario popular. Ha avanzado la historiografía de una manera muy notable, sin ninguna duda, pero quizás no ha avanzado tanto la difusión de todos estos pasos adelante que han ido dando los historiadores. Y es éste, en mi opinión, un importante reto pendiente que nos debe preocupar. Cabe esperar que la movilización de estudios, de aportaciones y de eventos que acompañará la conmemoración de este $\mathrm{V}$ centenario de su nacimiento permitan cambiar esta otra realidad que todavía persiste. Debiera ser éste uno de los objetivos: que la superación del retrato teresiano definido por el rapto y el extásis sea definitiva, en términos historiográficos y sociales.

El dossier de trabajos que presentamos plantea ofrecer nuevas contribuciones al conocimiento histórico de Teresa de Jesús y de su proyección y legado. La propuesta se orienta en una doble dirección. Por un lado, se plantea el estudio y la reinterpretación de algunas facetas importantes de su trayectoria vital, pero también hemos creído oportuno presentar otra perspectiva que contemple a santa Teresa desde lo que fue su impacto, abordando algunos aspectos de lo que fue la huella que dejó y la que se construyó, atendiendo a la difusión de su legado fuera de España, así como a la formación/deformación -histórica- de su imagen y a las polémicas en las que su figura se vio envuelta.

Ha latido en la concepción de este monográfico enfocar el estudio de santa Teresa y de su impacto desde las perspectivas abiertas por algunas de las líneas de investigación más actuales, desde los ámbitos de especialización historiográfica que ahora mismo están concitando un interés muy notable y se vienen desarrollando con una gran vitalidad, dentro y fuera de nuestras fronteras. Me refiero a la historia de la Corte, a esta historia tan renovada sobre el universo político y cortesano. Me refiero también a las riquísimas aportaciones que se vienen ofreciendo sobre las biografías femeninas en el terreno de confluencia de la historia de las mujeres y de la historia social de la cultura, incorporando

místicos. Teresa de Jesús y Juan de la Cruz: 45-60. Salamanca: Universidad Pontificia. Igualmente, S. Ros afirmaba la «definitiva superación de una larga historia barroca y de la tradicional visión hagiográfica en las que hasta no hace mucho permanecía aherrojada la figura de santa Teresa». Ros García, S. 1997. «Presentación», en S. Ros García (coord.); La recepción de los místicos. Teresa de Jesús y Juan de la Cruz: 13-21. Salamanca: Universidad Pontificia. La cita en p. 17. 
igualmente las cuestiones del interés que pervive por los temas de construcción de la memoria y de la identidad. También es bien reciente la historia de las emociones, la historia de los afectos y de los sentimientos, un campo que todavía tiene espacio para explorar y para la innovación. Estos son algunos de los terrenos transitados con Teresa de Jesús en el norte, desempolvando en algunos casos fuentes documentales que han estado marginadas o poco consideradas hasta no hace mucho tiempo, revisando planteamientos, ofreciendo perspectivas innovadores y desmenuzando recorrido historiográfico sobre asuntos que claramente lo estaban reclamando.

El profesor Teófanes Egido, a quien ya me he referido en las primeras líneas como uno de los mejores conocedores de santa Teresa y de la historiografía teresiana, nos ofrece en su artículo un trabajo que nos introduce en una faceta novedosa de la madre Teresa al mismo tiempo que contribuye al impulso de esa línea de investigación de reciente desarrollo que he mencionado arriba: la historia de los sentimientos, la historia de las emociones. En sus primeras líneas marca ya la importancia de hacer la historia de los sentimientos y alerta de sus dificultades, sobre todo cuando nos referimos a una época, la de la edad moderna, que no es la nuestra y más aún cuando tratamos de los sentimientos de los santos, de unos santos representados en biografías hagiográficas y, sobre todo, como bien plantea el profesor Egido, porque aquellas santidades eran incompatibles con la expresión de los sentimientos, que debían ser dominados, contenidos y ocultados. Las prácticas de mortificación tenían ese cometido.

Afortunadamente, el conocimiento de esta dimensión de la vida de Teresa es posible a través de su epistolario, de ese conjunto documental magnífico e insustituible que son las casi quinientas cartas suyas que se han conservado. La materia de los sentimientos naturalmente acoge numerosos asuntos y manifestaciones. Teófanes Egido acota aquí el tema a dos de ellos: el humor y la risa, por un lado, y la ternura, por otro.

El humor y la risa no formaban parte de los registros que marcaban el modelo de santidad barroco, al contrario: se promocionaba el rigor, los lloros, el don de lágrimas... Y, sin embargo, la madre Teresa manifiesta en sus cartas estar bastante alejada de estos convencionalismos. Se ríe y le gusta hacerlo, bromea, tiene sentido del humor y lo despliega, como se documenta bien en los textos seleccionados por Teófanes Egido que nos muestra así esta dimensión transgresora de la santa: «Puede decirse, si ello no sonara a anacronismo, que habría sido una transgresora consumada».

Los sentimientos de ternura y su manifestación expresa tampoco eran reconocidos en el prototipo de santidad de aquella época. No eran emociones habituales. Y también aquí Teresa se alejará del patrón marcado. El artículo nos ofrece una buena muestra de estas demostraciones de ternura hacia sus familiares naturales 
y hacia los frailes y monjas que formaban su familia religiosa. La preocupación por sus hermanos y sobrinos, la angustia y la inquietud por la prisión de fray Juan de la Cruz.... Las numerosas muestras de afecto, de cariño y de debilidad por las niñas en sus conventos -doña Casilda de Padilla, su sobrina Teresita, la hermana del padre Gracián, Isabel- desfilan por sus cartas abiertamente y por esta reflexión histórica que nos ofrece el profesor Egido, que nuevamente nos devuelve a la madre Teresa viva y vivaz, distanciada también en tantos aspectos de los moldes convenidos e impuestos en aquel siglo XVI.

El trabajo de José Martínez Millán esconde mucho más de lo que se refleja en su título. El profesor Martínez Millán, promotor de la activísima historiografía que viene renovando el perfil de la historia política y del mundo cortesano, nos ofrece aquí una construcción compleja, como compleja fue la realidad histórica, un armazón que enlaza la explicación de la reforma espiritual de santa Teresa con su relación con las facciones cortesanas de la monarquía de Felipe II. No está en el título, pero otro protagonista nuclear del trabajo es el Papado, naturalmente tan «presente» en el mundo político de las Cortes europeas de la época.

Creo que interpreto bien la aportación de José Martínez Millán si señalo que ésta se articula sobre la idea de lo que él ha llamado la «contradicción» de santa Teresa, la contradicción que está latiendo a lo largo de todo el texto y que se presenta muy explícitamente en su final. Una contradicción que tuvo muchísimo contenido de tensión: genealógica, espiritual, social y política.

La necesidad de explicar la reforma espiritual de santa Teresa conduce al autor a los inicios. José Martínez Millán subrayará el impacto que causó en Teresa su genealogía y ha estimado que en su explicación no sólo es importante remitir al contexto político y social del reino de Castilla en la baja Edad Media y plantear el problema social de los judeoconversos, que lo hace, sino que ha considerado que también es imprescindible atender a la reestructuración y la transformación ideológica y doctrinal que se fraguó en ese mismo período bajo medieval en el seno de la propia Iglesia, completando con esta aportación específica las perspectivas de este tema fundamental que, como es sabido, ha sido polémico y ha concitado cientos de páginas, durante mucho tiempo de dudoso rigor casi todas.

El trabajo avanza con el estudio de la trayectoria espiritual de Teresa y de la génesis del ideal religioso teresiano situando la cuestión en la tensión creada a partir de la tendencia consciente a buscar el apoyo y la orientación en los dominicos y la derivada de la lectura de los libros de espiritualidad «recogida», un panorama complejo que, sin embargo, se dibuja con claridad. Igual que se hace en el paso siguiente -central en el trabajo- en el que se analizarán las relaciones establecidas por la madre Teresa con los miembros del «partido castellano» en el seno de la Corte, vitales en la cristalización de su proyecto espiritual y 
reformista y se estudiarán también las desplegadas con el otro frente esencial para la materialización de sus planes: Roma y sus representantes. La complicada trama de las relaciones entre las dos instancias de poder-monarquía y papado-, a su vez, compitiendo por la dirección de las reformas religiosas en torno a sus propios intereses, sustentaría una parte del devenir de la «contradicción» de santa Teresa.

Por su parte, la profesora Ofelia Rey Castelao aborda en su artículo otro de los temas teresianos que han concitado mucho interés y que desde sus orígenes ha dado lugar a una nutrida literatura, acompañada de bastantes dosis de polémica, en buena medida porque polémico es en sí mismo el asunto tratado: la proclamación de Teresa de Âvila como compatrona de España, frente al defendido patronato único del apóstol Santiago.

El objetivo del artículo es estudiar la polémica en torno a la primacía del patronato poniendo la atención en lo que se escribió y se sigue escribiendo para analizar cómo se ha examinado la cuestión desde ángulos diferentes, de manera que Ofelia Rey nos ofrece no sólo un repaso de las líneas esenciales sobre las que discurrió la historia de las tres ocasiones -fallidas las tres- en las que se produjo la proclamación de Teresa como compatrona y los debates y discusiones que acompañaron estos intentos, sino que también pone orden y claridad en la bibliografía y en el tratamiento historiográfico de este tema controvertido.

La profesora Rey realiza un recorrido exhaustivo, reflejando bien la complejidad de los intereses que se desarrollaron en cada uno de los episodios y sus intersecciones, y guiado por la precisión y por el interés de no perder algo fundamental: el orden cronológico de los procesos concernidos en el asunto del patronato y el de la bibliografía sobre la cuestión. Esta forma de proceder le permite entonces mostrar cómo el tema del patronato teresiano y la polémica al respecto se ha ido convirtiendo en los estudios (sobre todo en las últimas décadas y en buena medida en el ámbito norteamericano) en algo bastante ajeno al problema de origen, cómo la cuestión se ha deformado, se ha «sobredimensionado», por utilizar su misma expresión, ante perspectivas que han privilegiado la explicación en términos políticos, obviando o minusvalorando las claves que aportan la documentación archivística y la bibliografía construida sobre ésta. También, esta revisión le permite llamar la atención sobre la importancia del primer evento del co-patronato teresiano, menos conocido, pero fundamental en tanto que contiene las claves de los episodios subsiguientes.

Cuando se termina de leer este trabajo se llega a la conclusión de que esta contribución que nos brinda Ofelia Rey era muy necesaria. Muestra que el tema no está agotado -el final en forma de preguntas así lo plasma- y pone de manifiesto que la historiografía necesitaba esta revisión sosegada y sólida, también ecuánime, de lo que se ha dicho y se ha escrito, de lo que se ha investigado y 
de lo que no y de los apoyos documentales y bibliográficos de quienes se han acercado -con unos intereses u otros- al tema del patronato de santa Teresa.

Era imprescindible que el llamado nuevo mundo tuviera su representación en este monográfico. Del establecimiento y de la transmisión de la espiritualidad y el legado teresiano al territorio americano se ha ocupado Asunción Lavrin, centrando su trabajo en el espacio del virreinato de Nueva España que fue, por otra parte, el ámbito en el que el Carmelo descalzo femenino dio sus primeros pasos. El primer convento se fundaría en Puebla en 1604. Las primeras cinco fundadoras se recibieron en 1606. A partir de esa fecha llegaron a instalarse hasta siete conventos en el virreinato, cuyas fundaciones repasa la autora, deteniéndose también en los conflictos que se generaron en torno a la autoridad episcopal que se estableció sobre ellos.

El núcleo del artículo pretende seguir las huellas de la presencia teresiana y de su legado en el territorio novohispano a través del estudio de las vivencias de las discípulas de Teresa de Jesús, las religiosas de aquellos siete conventos fundados. Mantiene Asunción Lavrin que la herencia teresiana, depositada en sus Reglas y en la observancia de las mismas, fue seguida en sus líneas esenciales por aquellas carmelitas descalzas, orgullosas de serlo, pero la aportación fundamental de su trabajo es mostrarnos cómo el carisma y la espiritualidad teresiana vivieron un proceso de transformación y de acomodación a las circunstancias concretas y al contexto de aquel mundo y de aquella época. Las formas de manifestar la vivencia religiosa y espiritual de quienes habían bebido en los libros de Santa Teresa y adoptado sus códigos se tiñeron de los signos del barroquismo postridentino. De alguna manera, lo que nos descubre Lavrin es cómo la espiritualidad de Teresa y sus propuestas vivenciales fueron en parte engullidas y deformadas por las formas de expresión de una religiosidad barroca, marcadamente exteriorizada. La locución «barroco teresiano» que ella utiliza en una ocasión me parece verdaderamente expresiva de esta realidad presente y visible en las biografías de las monjas novohispanas y en las crónicas religiosas, inundadas de referencias a experiencias visionarias, prácticas de mortificación o una notable presencia del demonio en la que muy posiblemente la madre Teresa no se hubiera reconocido.

El número de conventos de las carmelitas no fue destacado, pero Asunción Lavrin apunta muy certeramente cuando plantea que el peso y el impacto teresiano no debe medirse en términos fundacionales, sino en términos culturales.

Y, ciertamente, enfocado desde esta perspectiva, la influencia de santa Teresa revela toda su amplitud, pero también la entidad de las mudanzas y las alteraciones que sufriría su legado.

No podía faltar tampoco un trabajo sobre la presencia y la andadura de las carmelitas descalzas -«Le Teresiane»- en Italia. El artículo firmado por Sara 
Cabibbo y Elisabetta Marchetti cubrirá esta representación italiana, pero es al mismo tiempo una magnífica muestra de las líneas de investigación de la historiografía más actual, como se apunta ya en su título. El texto se despliega en dos partes bien definidas. En la primera se plantea una introducción a la historia de la constitución de la Congregación descalza de Italia, separada de la española, perfilando bien lo que hubo de lucha de poderes Roma-Monarquía española en este episodio y la trascendencia del apoyo romano a esa Congregación, para pasar a trazar el cuadro de las fundaciones de las comunidades de descalzas en Italia desde el asentamiento genovés, atendiendo también al especial caso romano y comparando este proceso de expansión fundacional con el habido en Francia y Flandes para mostrar cómo la situación en Italia fue bien distinta; los superiores españoles abandonarían la atención hacia las casas italianas, y lo harían en primer lugar respecto a las femeninas. Igualmente diferente fue la opción del texto constitucional que se realizó entre las religiosas italianas y francesas, explicado en la trama compleja de intereses de los otros protagonistas -la orden, la monarquía, el papado.

La segunda parte del artículo propone un estudio de caso a partir de las dos primeras fundaciones de las carmelitas descalzas en Palermo, la capital del virreinato siciliano. Huyendo de cualquier planteamiento simple y descriptivo esta parte del trabajo entrecruza el interés de las relaciones trabadas de estos dominios italianos de los Austrias con la corte de Madrid, permitiendo mostrar cómo los monasterios femeninos fueron elementos importantes de esta historia del poder más amplia que interconectaba ambos espacios: los territorios italianos y la corte española, deviniendo, como se afirma, en «lugares de socialización, de «internacionalización» y de construcción de relaciones orientadas a la integración de sus clases dirigentes. En este marco, también los conventos se dibujaron como piezas estratégicas de los intereses de las familias que los promovieron. «Dos familias, dos monasterios» es el significativo título de uno de los epígrafes. Las dos fundaciones de Palermo fueron impulsadas por mujeres de la alta aristocracia y ambas fueron objetos de litigios y de «negocios». También en ambos se construiría una memoria hagiográfica que vinculaba comunidad religiosa, familia, élites y santidad, en la que la huella teresiana era evidente. Cierra el trabajo el análisis del contenido de las biografías de Maddalena di Sant'Agostino y de Geltrude di Gesù Maria. Ambas se presentarán como verdaderas hijas de santa Teresa, y no sólo en atributos de santidad barroca, sino también en sus comportamientos, en la elección consciente de su destino religioso, en sus capacidades o en su espíritu de lucha y de superación frente a las adversidades y los conflictos más terrenales.

Finalmente, el artículo que lleva mi firma pretende estudiar distintas facetas de la presencia de Teresa como referente en las crónicas de la orden religiosa, atendiendo a una parte muy específica de las mismas que no ha recibido 
demasiada atención por parte de los historiadores: las páginas que se dedicaron al recuerdo y a la semblanza biográfica de las religiosas más destacadas. Efectivamente, fue éste otro de los escenarios textuales en los que se presentó y representó la figura de la madre fundadora. Son muchas las biografías de carmelitas descalzas en las que la santa hará su aparición, y nos ha interesado mostrar cómo a través de estos relatos se construyó y se alimentó también la imagen de santa Teresa, añadiéndose material para el conocimiento de su vida, pero sobre todo, incorporando sustancia para esa continuada reelaboración de su figura, de su mito, de su memoria.

Estudiamos en nuestro trabajo cuáles fueron los ingredientes de ese retrato teresiano que se fue reflejando y presentando en las narraciones biográficas de quienes fueron sus hijas, poniendo de manifiesto cómo, al lado de la dimensión «milagrosa» y de la faceta sobrenatural de Teresa, estos textos enfatizan mucho la dimensión más humana y terrenal. La Teresa que sobresale es la mujer con autoridad, la fundadora y emprendedora, la organizadora, la mujer de acción y de gobierno, la de mirada atenta y vigilante a todos los asuntos que pudieran afectar a sus conventos y a sus proyectos reformistas, la mujer que se relacionaba con el resto del mundo social, que lidiaba con los poderes eclesiásticos y seculares.

Y, efectivamente, es posible ver cómo están presentes los rasgos de la que fue la santa Teresa real: la fundadora, la priora, la reformadora, la política, también la que ejerció el papel de «madre» para con sus hijas. Quisiera subrayar aquí que todos estos ingredientes que se muestran en las crónicas son reflejos y presencias de una Teresa real, que muchos de los teresianistas han ignorado a lo largo del tiempo en beneficio de una imagen de Teresa adaptada a la hagiografía. Y esta Teresa, tan alejada de las concepciones establecidas sobre las mujeres en aquella época y de los papeles que se les asignaban, también se cuela en las páginas de los cronistas. Está ahí, para quien quiera verla.

Y al margen ello, también estos textos ofrecen otras posibilidades interpretativas y nos han permitido hacer otras lecturas acerca del protagonismo de santa Teresa en estas biografías que nos ocupan. En ellas aparecen todos los conventos y cabe pensar que el eco de su presencia y de sus intervenciones excedía los muros de aquellos claustros, que alimentaron su fama y prestigio con estos materiales y que se convertirían en tradiciones difundidas y muy cuidadas por la comunidad, parte de su identidad. Lo mismo que otras alcanzaron un rango más amplio: el de tradiciones del conjunto de la orden. Esta otra dimensión ha completado el trabajo que presentamos. 